\title{
COMPARAÇÃO E VIABILIDADE DE DIFERENTES TIPOS DE RASTREADORES SOLARES PARA GERADORES FOTOVOLTAICOS
}

\section{ARTIGO ORIGINAL}

RODRIGUES, Luan Carlos ${ }^{1}$, FIGUEIRA, Helem Borges²

RODRIGUES, Luan Carlos. FIGUEIRA, Helem Borges. Comparação e viabilidade de diferentes tipos de rastreadores solares para geradores fotovoltaicos. Revista Científica Multidisciplinar Núcleo do Conhecimento. Ano. 06, Ed. 12, Vol. 08, pp. 102-126. Dezembro de 2021. ISSN: 2448-0959, Link de acesso: https://www.nucleodoconhecimento.com.br/engenharia-eletrica/rastreadores-solares, DOI: $\quad 10.32749 /$ nucleodoconhecimento.com.br/engenharia-eletrica/rastreadoressolares

\section{RESUMO}

Em meio às buscas por fontes de energias cada vez mais limpas e eficientes, a energia solar, em especial a fotovoltaica, está cada vez mais sendo utilizada por não poluir e apresentar uma forma rápida e barata de conversão em eletricidade, isso faz com que sua produção aumente gerando um ciclo de redução de preços. Uma forma de aumentar a eficiência desses painéis é a instalação de mecanismos, conhecidos como rastreadores solares ou trackers, que são capazes de fazer com que o sistema siga a movimentação do Sol, mantendo as placas fotovoltaicas o mais perpendicular possível aos raios solares. Foi verificada a viabilidade de investimento nos diversos tipos de estruturas existentes estudadas em diferentes artigos utilizando ferramentas como VPL, TIR e Payback. Utilizando as médias encontradas de eficiência, custos de investimentos, manutenção e consumo e comparando com sistemas que não utilizam rastreadores solares, foi verificado que o investimento nessas configurações

\footnotetext{
${ }^{1}$ MBA em engenharia e gestão de energias renováveis, Engenheiro eletricista.

${ }^{2}$ Orientador.

RC: 103710

Disponível em: https://www.nucleodoconhecimento.com.br/engenhariaeletrica/rastreadores-solares
} 
não se tornaria viável, porém, em determinados casos, poderiam ser encontrados na atualidade opções viáveis de rastreadores.

Palavras-chave: Energia fotovoltaica, rastreador solar, viabilidade.

\section{INTRODUÇÃO}

Já há alguns anos, o mundo vem buscando por fontes alternativas de energia, tanto como proteção da escassez de recursos ou opções de menor custo, mas o mais importante é a busca por recursos menos poluentes e sustentáveis. Existem muitas fontes de energias alternativas que podem ser usadas no lugar de combustíveis poluentes como os fósseis, por exemplo. Para a escolha de qual fonte de energia utilizar, deve-se levar em consideração fatores econômicos, ambientais e de segurança, assim, a energia solar tem grande potencial dentre as outras fontes de energia alternativa por ser sustentável e limpa, (KALOGIROU, 2014). A energia proveniente do Sol, é infinita para nossa escala de tempo e ela é responsável, mesmo que indiretamente, por quase todas as outras fontes de energia no planeta, seja permitindo a fotossíntese nas plantas, promovendo o ciclo das águas e ventos ou até a origem do petróleo que não seria possível sem a sua influência. De forma mais técnica, a energia solar hoje é dividida entre térmica e fotovoltaica. (PINHO; GALDINO, 2014).

É conhecida como fotovoltaica a energia que é transformada diretamente da luz em eletricidade através de painéis de silício e que hoje vem aumentando sua popularidade. Com a motivação de sempre conseguir formas mais eficientes, baratas e menos poluentes de energia, o objeto desse estudo são as estruturas de rastreadores solares (trackers) instaladas em painéis fotovoltaicos, que são mecanismos que fazem com que as placas sigam a movimentação do Sol, através de sensores ou algoritmos, mantendo os painéis o mais perpendicular possível em relação aos raios solares, aumentando a eficiência do sistema. Contudo, toda essa estrutura gera maiores custos de investimento, consumo e manutenção, tornando-se

RC: 103710

Disponível em: https://www.nucleodoconhecimento.com.br/engenhariaeletrica/rastreadores-solares 
necessário verificar a viabilidade dessas instalações, uma vez que existem diversos tipos estruturas, custos e formas de rastreamento.

Através do estudo de vários artigos a respeito, foram levantadas médias dos valores encontrados de investimento, consumo, eficiência e manutenção e comparados com sistemas que não utilizam rastreadores, a fim de analisar até que ponto se tornaria viável um investimento nessa tecnologia. Foram utilizadas ferramentas econômicas como VPL, TIR e Payback, que permitiram a comparação entre sistemas e estudos, fornecendo resultados mais precisos de viabilidade do investimento.

\section{O CENÁRIO DA ENERGIA SOLAR FOTOVOLTAICA}

Segundo o International Renewable Energy Agency, (DATA, 2019), a capacidade acumulada mundial de eletricidade renovável cresceu $7,4 \%$ no ano de 2019 , saindo de 2,361 GW para 2,537 GW, podemos ver esse aumento constante na figura 1. A geração de eletricidade por energias renováveis já representava 26,3\% (6.523 TWh) de toda eletricidade gerada no mundo em 2018, segundo a National Renewable Energy Laboratory, (RENEWABLE, 2018)

Figura 1. - Tendências em Energias Renováveis no mundo.

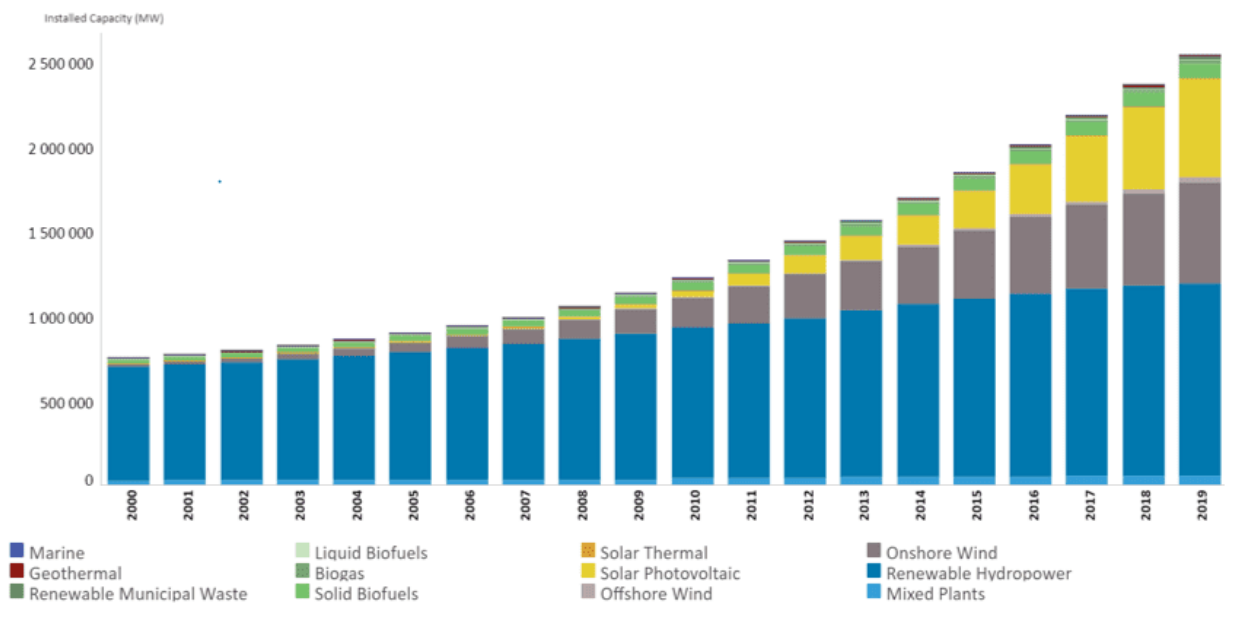

Fonte: DATA, 2019.

RC: 103710

Disponível em: https://www.nucleodoconhecimento.com.br/engenhariaeletrica/rastreadores-solares 
No Brasil, podemos notar a baixa parcela de outras fontes de energias renováveis frente à grande representatividade da fonte hídrica de geração, figura 2, porém com um aumento significativo na produção de energia solar fotovoltaica.

Figura 2. - Tendências em Energias Renováveis no Brasil.

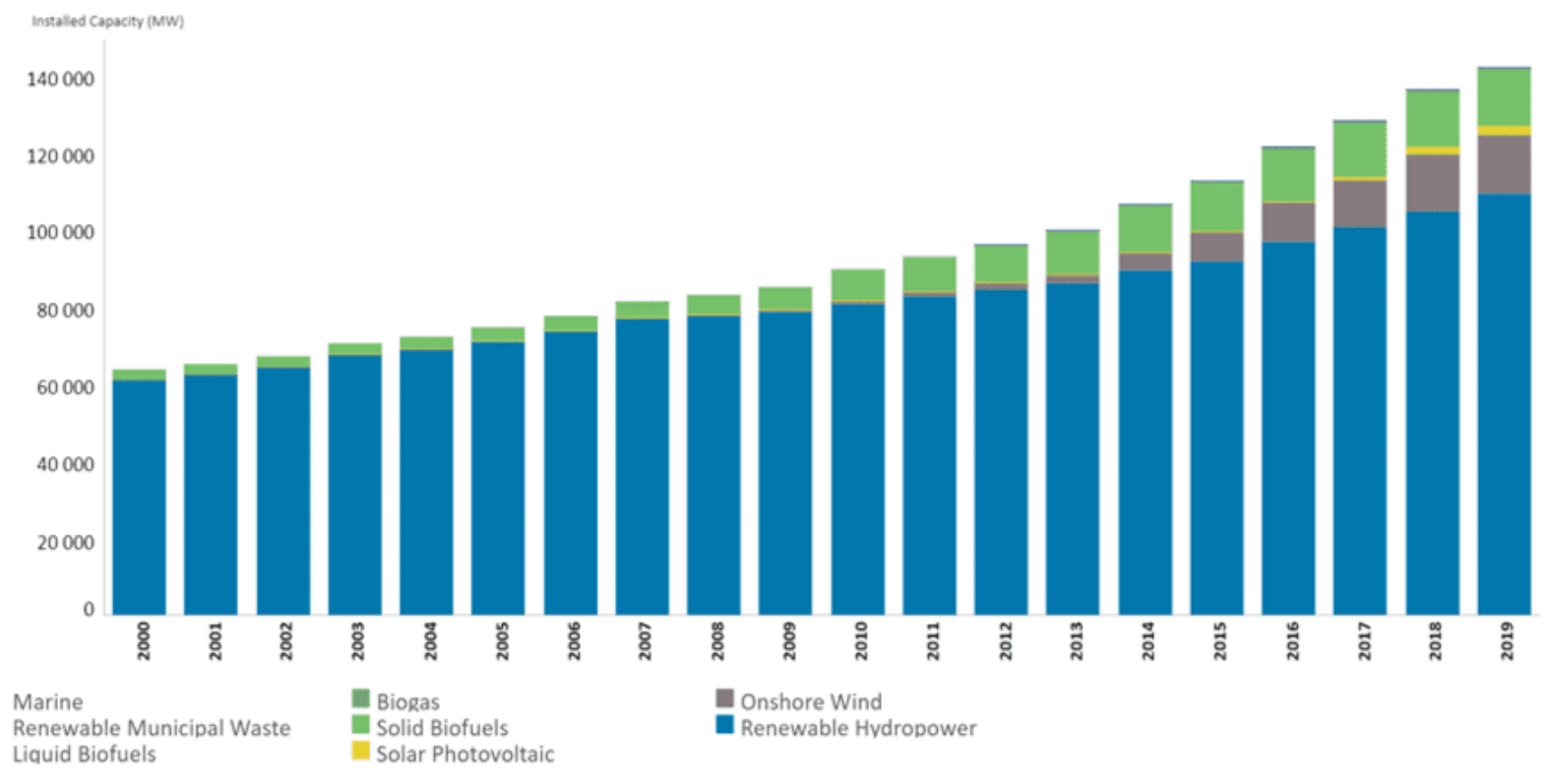

Fonte: DATA, 2019.

Pôde-se notar um aumento do interesse da tecnologia no ano de 2013 na figura 3, parte por contribuição da Resolução Normativa da ANEEL n 482/2012, permitindo o consumidor a geração de sua própria energia através de energias renováveis e posteriormente com a Resolução Normativa $n^{\circ}$ 687/2015, determinado a micro e minigeração distribuída e passando o sistema de créditos de 36 para 60 meses do excedente gerado, entre outras facilidades que contribuíram para o incentivo da instalação dos sistemas fotovoltaicos. (ANEEL, 2018). 
Figura 3. - Tendências em Energias Renováveis no mundo.

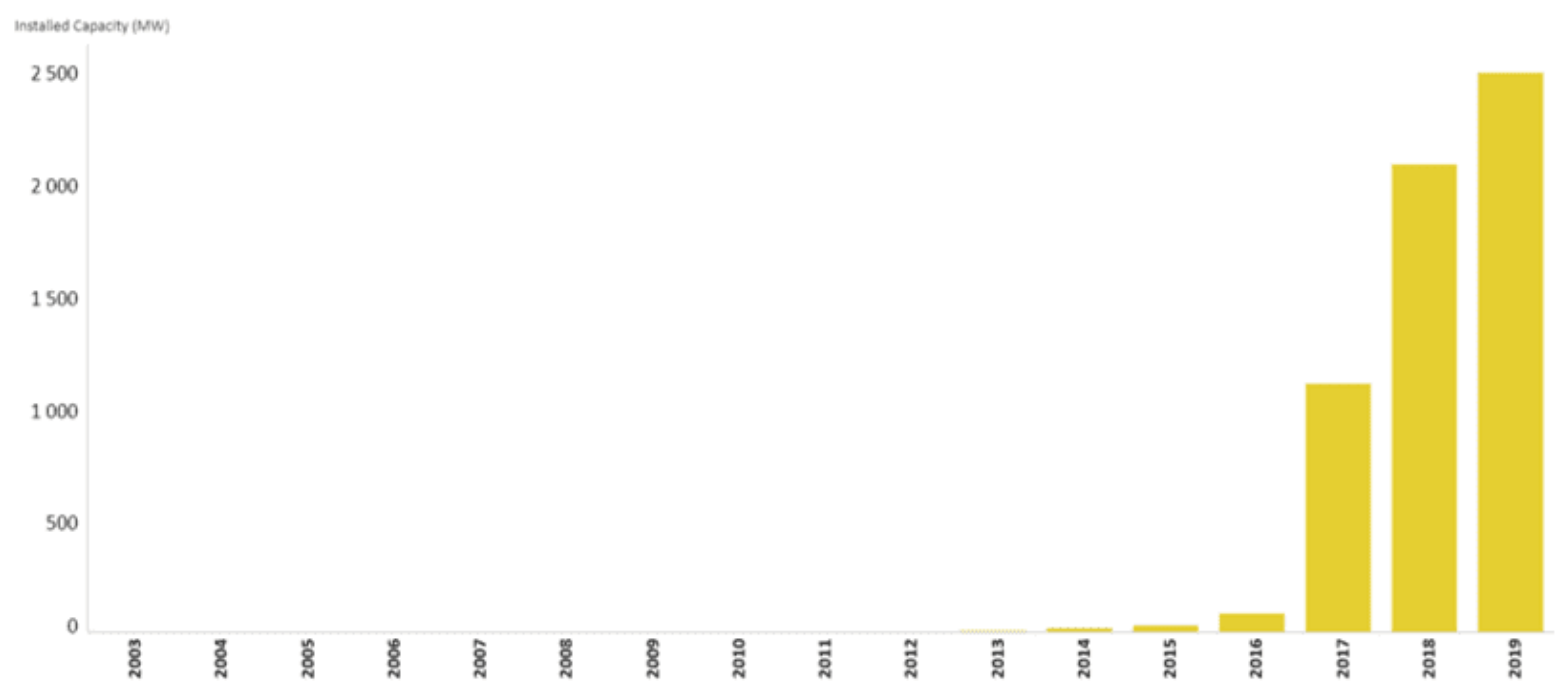

Fonte: DATA, 2019.

Outro fator que contribui para a utilização dessa tecnologia é a localização do país, o Brasil se encontra em uma geografia favorável para os índices de irradiação solar, como visto na figura 4, com valores de irradiação direta normal de 3,01 a 6,22 $\mathrm{KWh} / \mathrm{m}^{2}$, (GLOBAL, 2020).

Figura 4. - Irradiação Normal Direta.

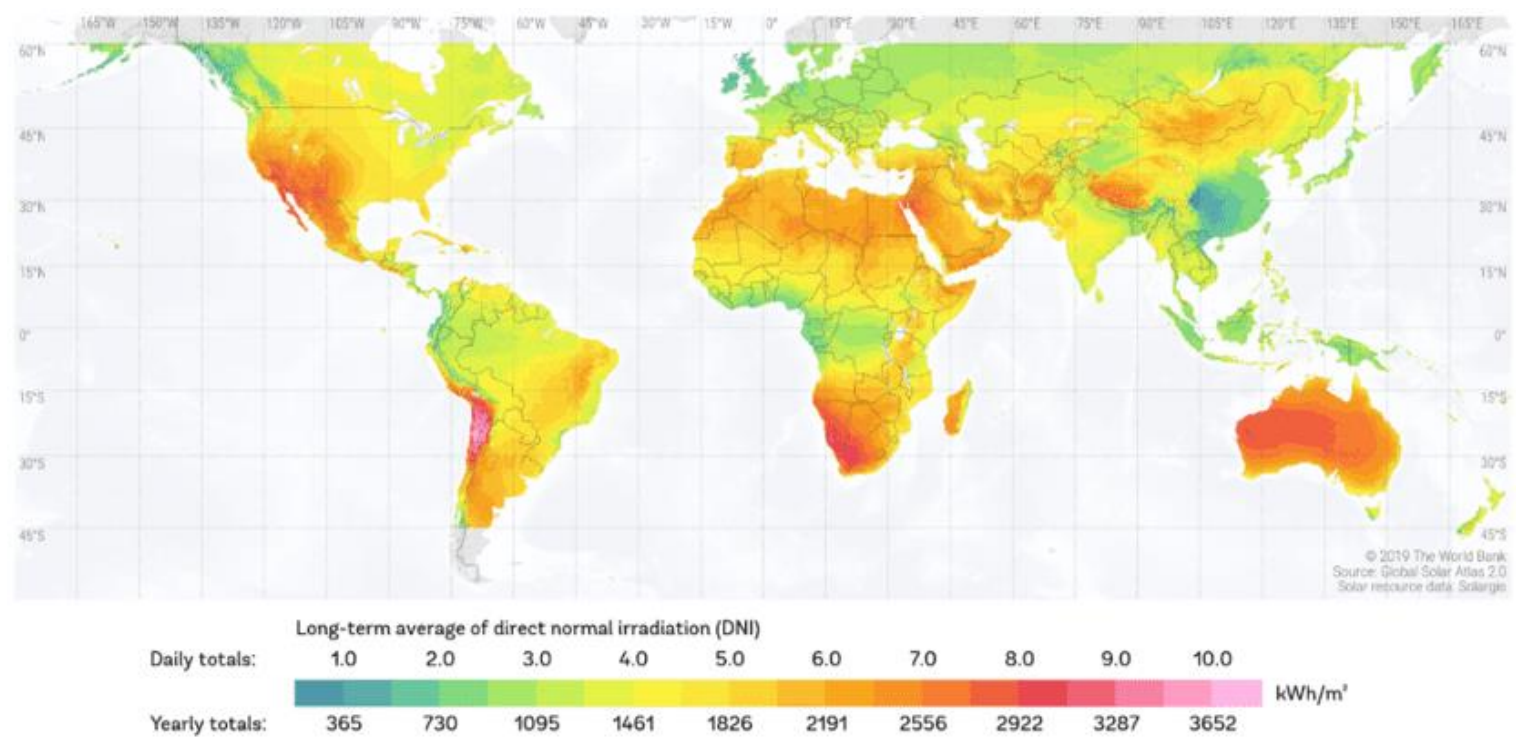

Fonte: GLOBAL, 2020.

RC: 103710

Disponível em: https://www.nucleodoconhecimento.com.br/engenhariaeletrica/rastreadores-solares 
Cada vez mais com as melhorias da tecnologia e do aumento da produção, conseguem-se módulos fotovoltaicos mais eficientes e com menor custo, o que torna a tecnologia mais atrativa, outro fator importante são as medidas governamentais e incentivos através de financiamentos, tornando essa modalidade mais acessível. Nas figuras 5 e 6 vemos a evolução dos preços de diferentes tecnologias de células fotovoltaicas e a evolução do fator de capacidade da tecnologia.

Figura 5. - Custos dos módulos fotovoltaicos 2010-2018.

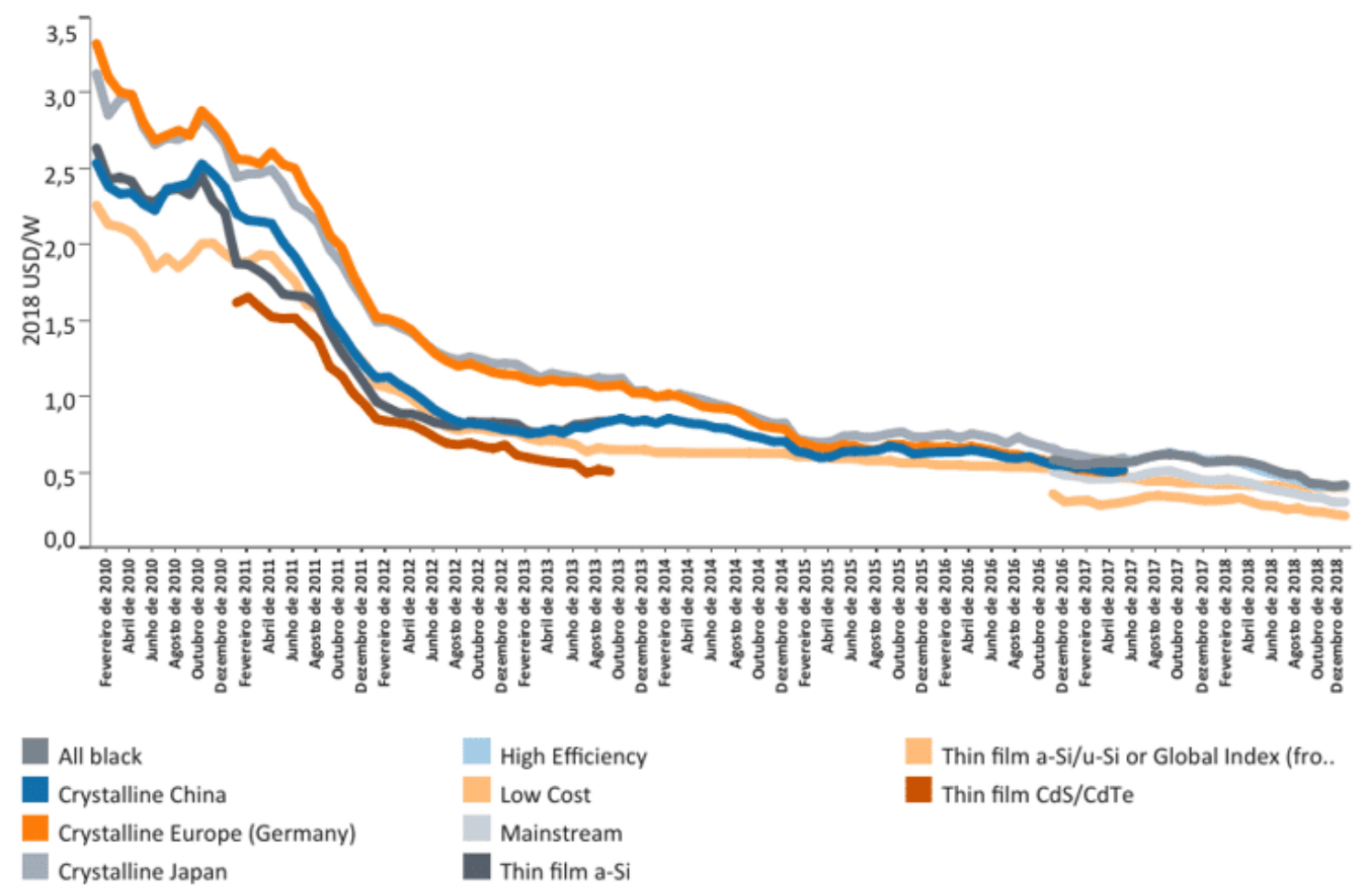

Fonte: DATA, 2019.

RC: 103710

Disponível em: https://www.nucleodoconhecimento.com.br/engenhariaeletrica/rastreadores-solares 
Figura 6. - Fator de capacidade 2010 - 2018.

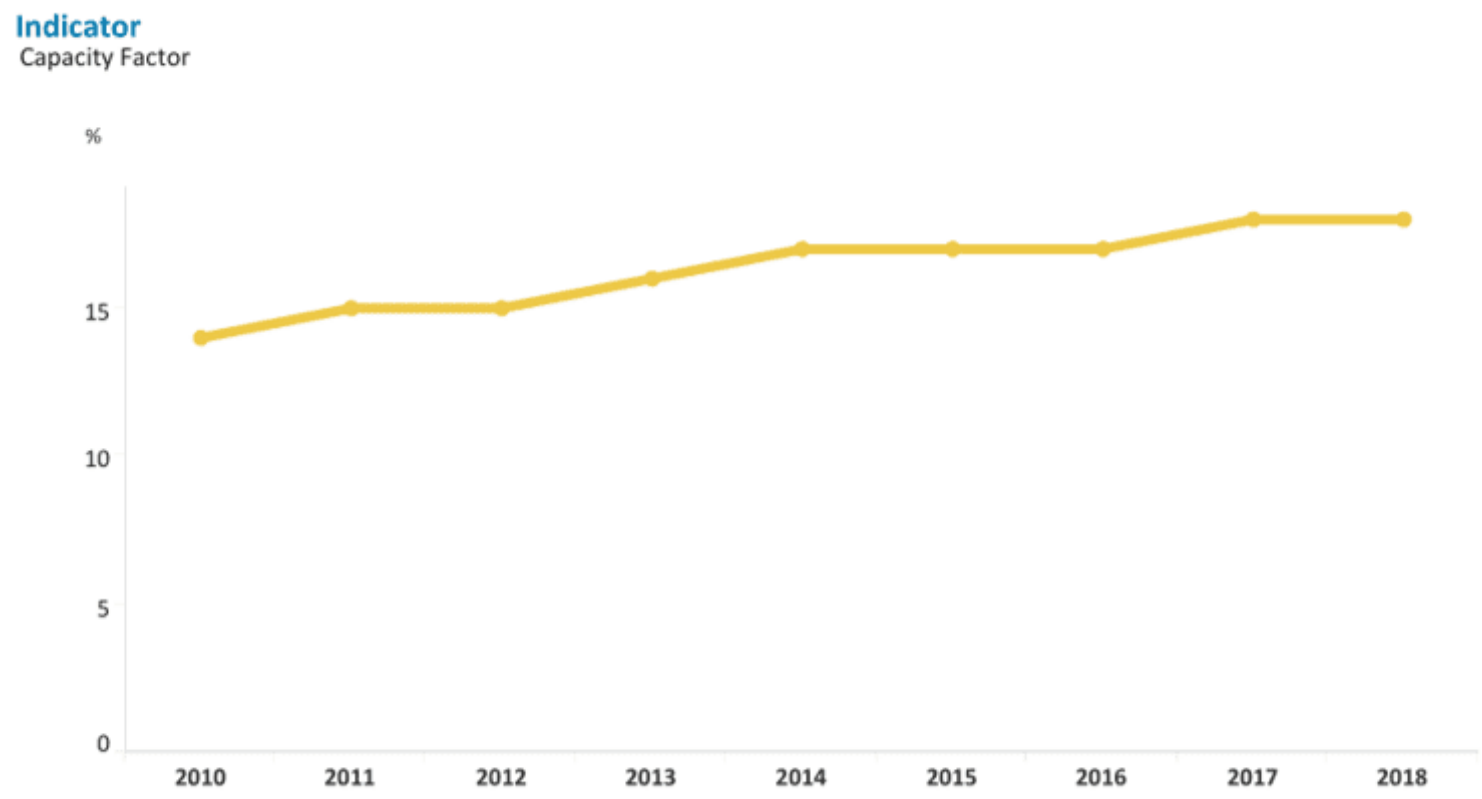

Fonte: DATA, 2019.

\section{ENERGIA SOLAR FOTOVOLTAICA E SEU FUNCIONAMENTO}

O efeito fotovoltaico foi descoberto por Edmond Bequerel, em 1839, onde foi notada uma diferença de potencial nos terminais de uma célula eletroquímica causada pela absorção de luz, porém foi apenas em 1956 que se começou a produzir industrialmente por diversos fatores incentivadores, como inicialmente as telecomunicações, a corrida espacial, a crise do petróleo e hoje a redução de fontes poluentes de energia. (PINHO; GALDINO, 2014)

A conversão direta da luz em eletricidade é conhecida como energia fotovoltaica. $O$ principal componente de geração dessa energia é conhecido como célula fotovoltaica, um componente composto de um material semicondutor, geralmente o silício. Dentre as diversas tecnologias e materiais utilizados para fabricação dessas células, os mais comuns são o silício monocristalino $(\mathrm{m}-\mathrm{Si})$ e o silício policristalino (p-Si), representando mais de $85 \%$ do mercado. (PINHO; GALDINO, 2014).

RC: 103710

Disponível em: https://www.nucleodoconhecimento.com.br/engenhariaeletrica/rastreadores-solares 
Segundo Kalogirou (2014), os módulos fotovoltaicos são dispositivos de estado sólido que convertem luz em eletricidade e por não terem partes móveis, sua manutenção é mínima e vida útil longa, não gera gases e por terem uma estrutura modular, podem ser conectados quantos painéis forem necessários para se atingir uma determinada potência de saída. Os módulos são compostos de duas ou mais finas camadas de material semicondutor, geralmente silício, cujos átomos possuem 4 elétrons na sua última órbita, quando se adiciona ao silício um material de 5 elétrons na última camada (fósforo por exemplo), em um processo conhecido como dopagem, sobra-se um elétron na combinação, fazendo o material ficar negativamente carregado, o chamamos de cristal $n$. $O$ oposto ocorre ao dopar o silício com uma substância de 3 elétrons na última camada, o material fica com falta de um elétron na combinação, tornando-se positivamente carregado e consequentemente chamado de cristal $p$. Quando se adiciona um cristal $n$ de um lado de um substrato de silício e $p$ do outro, ocorre o que conhecemos como junção $p n$, nela ocorre a passagem de elétrons e lacunas de um lado para outro formando uma camada permanente de diferença de potencial. Se a energia dos fótons que atingir essa região for maior que a energia necessária para vencer esse gap de energia e se os criais $p$ e $n$ forem conectados eletricamente, surgirá então uma corrente circulando nesse material, (ALCÂNTARA, 2013). Como a corrente gerada pelos módulos fotovoltaicos é contínua, é comum a utilização de inversores para deixá-la alternada e adequada para a utilização dos consumidores finais.

\section{RASTREAMENTO SOLAR}

Sabemos que a Terra faz dois movimentos principais conhecidos como translação, onde ela orbita em torno do Sol e de rotação, onde ela gira em seu próprio eixo. Segundo Kalogirou (2014) a Terra tem uma excentricidade baixa em sua órbita $(0,01673)$, sendo praticamente circular, e um ângulo de inclinação de $23,45^{\circ}$, tendo um dia com aproximadamente $24 \mathrm{~h}$. Portanto a posição do Sol depende basicamente do horário, do dia do ano, da latitude e longitude do local. Veremos, portanto, em

RC: 103710

Disponível em: https://www.nucleodoconhecimento.com.br/engenhariaeletrica/rastreadores-solares 
Alves (2008) e Kalogirou (2014) algumas equações necessárias que determinam a posição do Sol no plano terrestre.

\section{1 ÂNGULO HORÁRIO}

O ângulo horário ( $\omega)$, equação (1), é determinado de acordo com um dia de $24 \mathrm{~h}$, onde às $12 \mathrm{~h} 00$ o Sol está posicionado a $0^{\circ}$ e a cada hora seu ângulo muda 15ㅇ․

$$
\omega=15\left(t_{s}-12\right)
$$

Com $t_{s}$ sendo a hora solar medida em horas de 0 a 24

\subsection{EQUAÇÃO DO TEMPO}

Durante o ano, ocorre uma diferença entre a hora solar média e a hora solar real que pode variar \pm 17 minutos, como descreve a equação (2), Equation Of Time.

$$
\text { EOT }=0,258 \cos (x)-7,416 \operatorname{sen}(x)-3,648 \cos (2 x)-9,228 \operatorname{sen}(2 x)
$$

(2)

Onde $x$, por sua vez, é um ângulo expresso em graus e dependente do dia do ano $(M)$, que varia de 1 a 365 , como descreve a equação (3).

$$
x=\frac{360(N-1)}{365,242}
$$




\subsection{CONVERSÃO DO TEMPO}

Através da equação (4), obtém-se a conversão da hora solar e do relógio.

$$
t_{s}=L C T+\frac{E O T}{60}-L C-D
$$

(4)

Onde LCT é a hora do relógio local (Local Clock Time), $t_{s}$ a hora solar expressa em horas, EOT a equação do tempo, LC é a correção da longitude calculada na equação (5) também expressa em horas e D é igual a 1 ou 0 caso a região esteja em horário de verão ou não respectivamente.

$$
L C=\frac{L L-L M}{15}
$$

Com $L L$ sendo a longitude do local e $L M$ a longitude do meridiano do fuso horário local.

RC: 103710

Disponível em: https://www.nucleodoconhecimento.com.br/engenharia- 


\section{4 ÂNGULO DE DECLINAÇÃO}

Segundo Kalogirou (2014), a Terra possui um ângulo entre o eixo de rotação e o eixo da eclíptica de $23,45^{\circ}$.O ângulo formado entre a linha imaginária que liga o centro da Terra com o Sol e o plano equatorial é conhecido como ângulo de declinação (ס), ilustrado pela figura 7. Conforme o planeta orbita o Sol durante o ano, essa declinação varia de $-23,45^{\circ}$ a $23,45^{\circ}$ obedecendo a expressão (6), onde $\mathrm{N}$ é o dia do ano.

$$
\delta=23,45 \operatorname{sen}\left(\frac{360}{365}(284+N)\right)
$$

Figura 7. - Declinação terrestre.

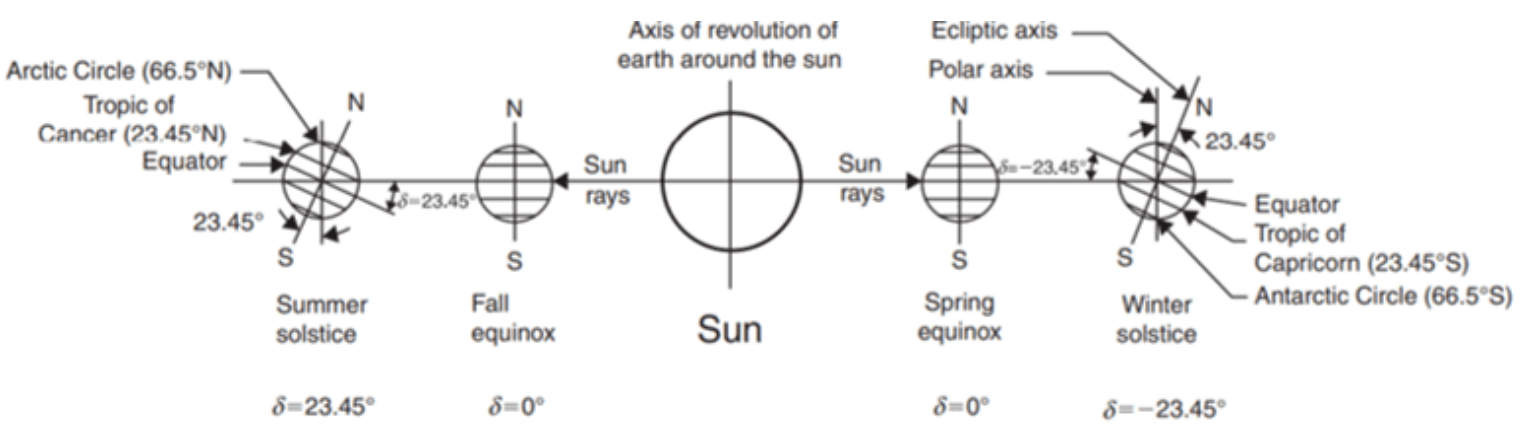

Fonte: KALOGIROU, 2014.[/caption]

\section{5 ÂNGULO DE ALTITUDE SOLAR}

Um dos ângulos componentes da posição do Sol é o ângulo de altitude $(\alpha)$ que é formado entre os raios solares e o plano horizontal mostrados na figura 8 e expresso na equação (7). 
Figura 8. - Ângulos das coordenadas solares.

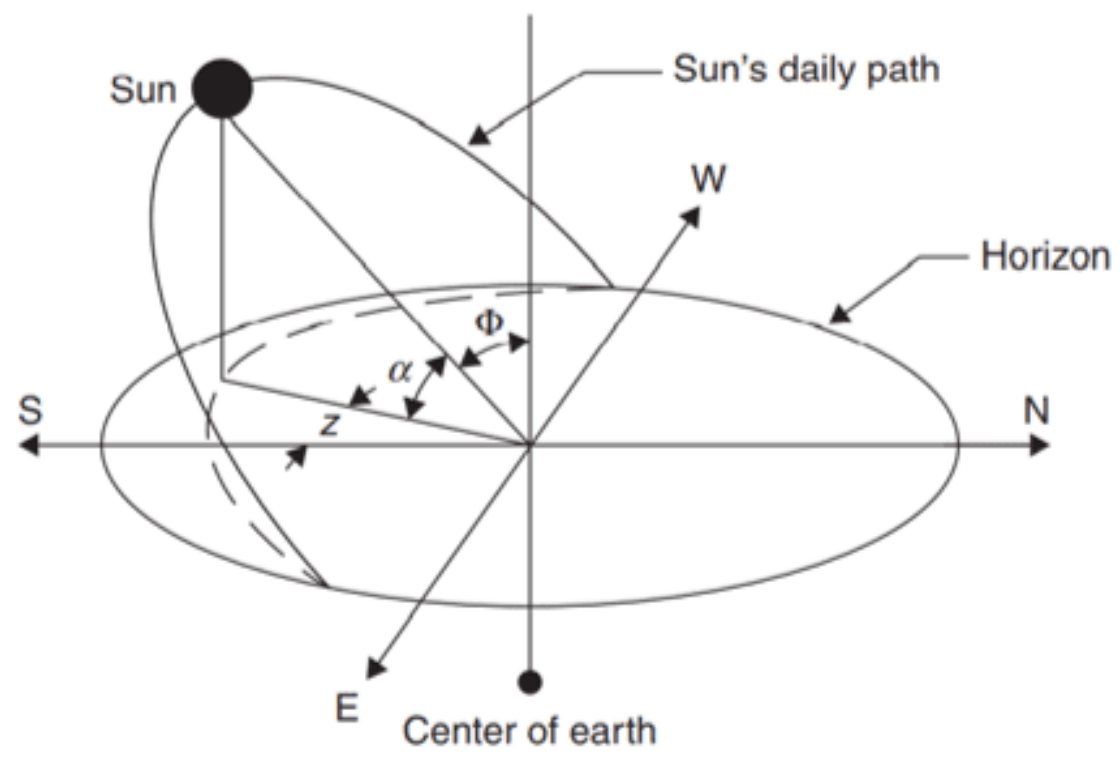

Fonte: KALOGIROU, 2014.

$$
\operatorname{sen}(\alpha)=\operatorname{sen}(L) \operatorname{sen}(\delta)+\cos (L) \cos (\delta) \cos (\omega)
$$

(7)

Onde L é a latitude local.

RC: 103710

Disponível em: https://www.nucleodoconhecimento.com.br/engenhariaeletrica/rastreadores-solares 


\section{6 ÂNGULO DE AZIMUTE}

Também na figura 8 vemos que o ângulo de azimute (z) é formado entre o Sul ou Norte (dependendo do hemisfério do local) com o Sol, sendo assim a componente horizontal dos raios solares no plano, onde é $0^{\circ}$ às $12 \mathrm{~h}$. Esse ângulo é descrito pela expressão (8)

$$
\operatorname{sen}(z)=\frac{\cos (\delta) \operatorname{sen}(\omega)}{\cos (\alpha)}
$$

Utilizando as equações mencionadas, é possível criar algoritmos responsáveis por manter a estrutura do rastreador sempre na direção do Sol e ainda através de cálculos, determinar o ângulo de incidência dos raios solares.

\section{SISTEMAS DE RASTREADORES SOLARES}

Um sistema rastreador solar, também conhecido como tracker, é um dispositivo capaz de seguir a posição do sol durante o dia e ano. As formas mais comuns de rastreamento são por sensores que detectam a maior luminosidade, os chamados LDRs (Light Dependent Resistor), ou por algoritmos, formados pelas fórmulas antes apresentadas. Motores são responsáveis pela movimentação dessa estrutura, que se movimentam em certos intervalos de tempo. Existem várias formas possíveis de se desenvolver um rastreador solar, eles podem ser de dois eixos (full tracking), ou seja, ele é capaz de seguir o Sol totalmente, sempre tendo $100 \%$ de perpendicularidade com os raios solares, ou podem ser de um eixo, se diferenciando pela posição de seu eixo (ou sentido de movimentação do painel) como N-S horizontal, L-O horizontal, ou N-S polar. Vemos essas estruturas na figura 9.

RC: 103710

Disponível em: https://www.nucleodoconhecimento.com.br/engenhariaeletrica/rastreadores-solares 
Figura 9. - Diferentes estruturas de trackers de único eixo (identificadas pelo sentido de movimento).

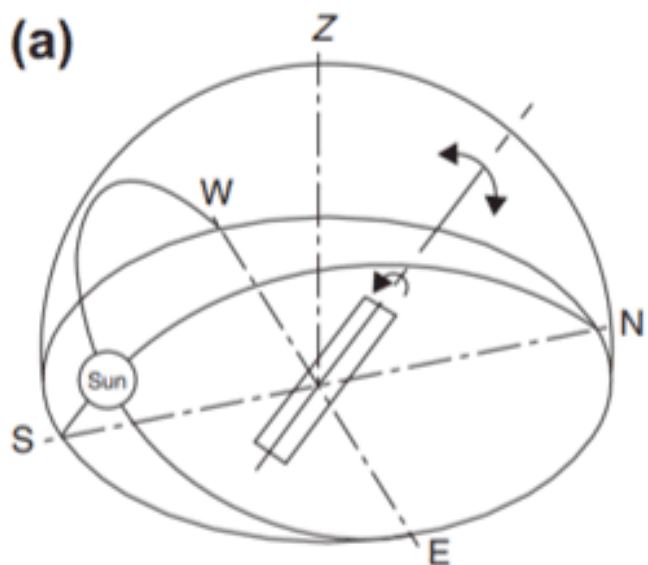

Full tracking

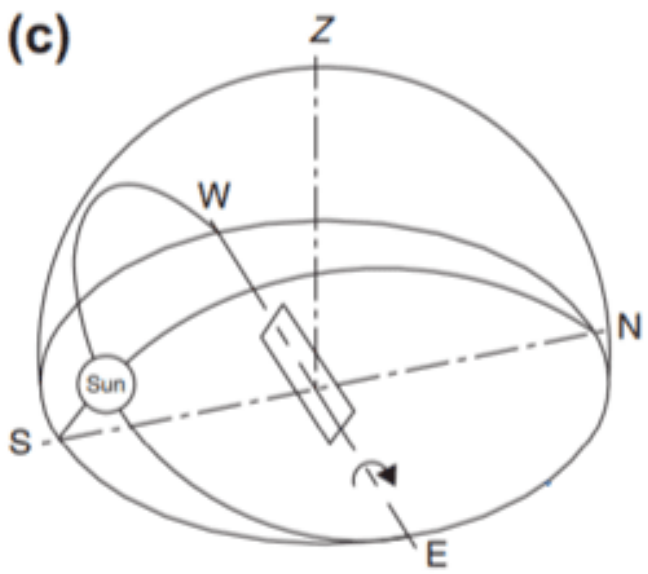

N-S horizontal

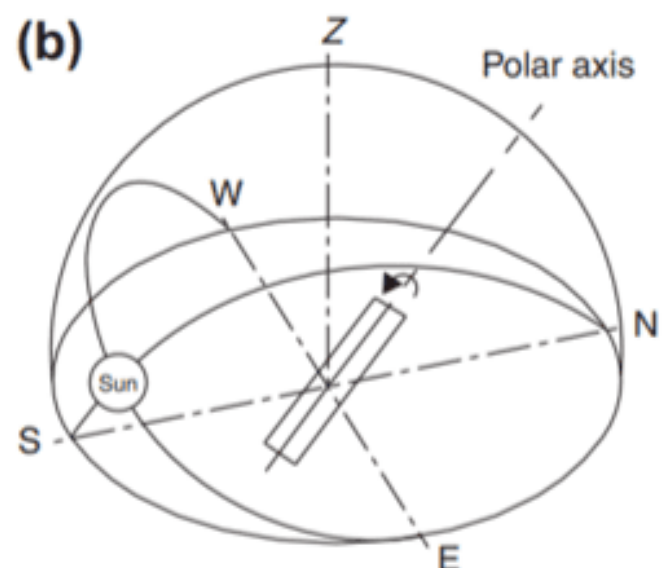

E-W polar

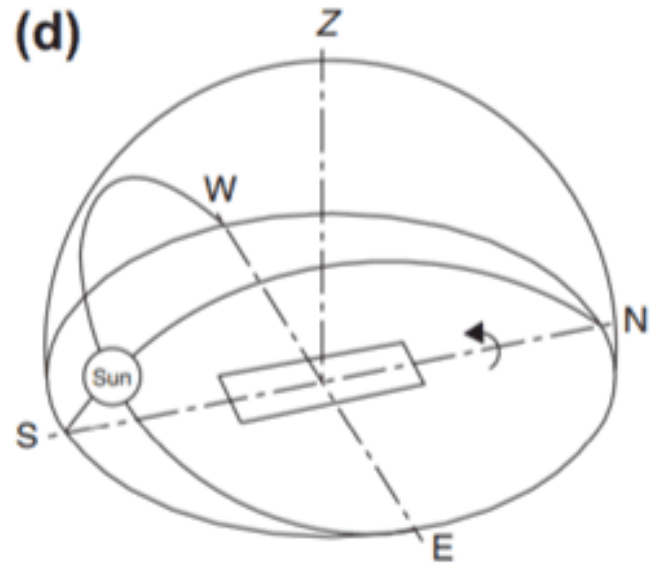

E-W horizontal

Fonte: KALOGIROU, 2014.

\section{ESTUDOS ECONÔMICOS}

\subsection{GANHO}

Kalogirou (2014) comparou a energia recebida nesses diferentes tipos de rastreadores na latitude de $35^{\circ} \mathrm{N}$, vemos na tabela 1 que o sistema de dois eixos (full tracking) tem $100 \%$ de aproveitamento da irradiação solar e que das estruturas

RC: 103710

Disponível em: https://www.nucleodoconhecimento.com.br/engenhariaeletrica/rastreadores-solares 
de um eixo a mais eficiente é a N-S polar (descrita como $E-W$ polar pelo seu sentido de rastreamento), onde a inclinação do painel é fixada na latitude do local.

Tabela 1. - Comparação da energia recebida por várias formas de rastreamento.

Table 2.2 Comparison of Energy Received for Various Modes of Tracking

\begin{tabular}{l|l|l|l|l|l|l} 
& \multicolumn{3}{c}{ Solar Energy Received $\left(\mathbf{k W h} / \mathbf{m}^{2}\right)$} & \multicolumn{3}{c}{ Percentage to Full Tracking } \\
\cline { 2 - 6 } Tracking Mode & E & SS & WS & E & SS & WS \\
\hline Full tracking & 8.43 & 10.60 & 5.70 & 100 & 100 & 100 \\
E-W polar & 8.43 & 9.73 & 5.23 & 100 & 91.7 & 91.7 \\
N-S horizontal & 7.51 & 10.36 & 4.47 & 89.1 & 97.7 & 60.9 \\
E-W horizontal & 6.22 & 7.85 & 4.91 & 73.8 & 74.0 & 86.2 \\
\hline E=equinoxes, SS = summer solstice, WS = winter solstice. \\
\hline
\end{tabular}

Fonte: KALOGIROU, 2014.

Outro experimento feito por Gutierrez et al (2020), compara as diferentes estruturas com um sistema fixo e apresenta o ganho em porcentagem. Vemos na tabela 2 esse resultado, onde tem-se um ganho de $33.8 \%$ do sistema de dois eixos em relação ao fixo e novamente a estrutura north-south tilted single axis (aqui identificada pela orientação do eixo) se torna mais eficiente, dentre as estruturas de um eixo, com um ganho de $27,7 \%$ sobre uma estrutura fixa. Um modelo diferente estudado pelo autor é o azimutal (vertical tilted single axis), no qual a base gira um painel inclinado à latitude acompanhando o ângulo azimutal do Sol.

Tabela 2. - Energia coletada por diferentes tipos de rastreadores.

\begin{tabular}{|c|c|c|}
\hline \multirow[b]{2}{*}{ Type of PV System } & \multicolumn{2}{|l|}{ ANNUAL } \\
\hline & Collected Irradiation $\left(\mathrm{kWh} / \mathrm{m}^{2} /\right.$ year) & Percentage Gain $(\%)$ \\
\hline Fixed & 2292 & 0.0 \\
\hline East-west horizontal single-axis & 2462 & 7.5 \\
\hline Vertical tilted single-axis & 2669 & 16.4 \\
\hline North-south horizontal single-axis & 2840 & 23.9 \\
\hline North-south tilted single-axis & 2927 & 27.7 \\
\hline Two-axes & 3067 & 33.8 \\
\hline
\end{tabular}

Fonte: Gutierrez et al, 2020.

RC: 103710

Disponível em: https://www.nucleodoconhecimento.com.br/engenhariaeletrica/rastreadores-solares 
Foram analisados diversos estudos de viabilidade com diferentes tipos de estruturas, na tabela 3 verificamos os ganhos conseguidos por esses experimentos, com uma média de ganho de $38,16 \%$ para sistemas de duplo eixo e 13,58\% para estruturas de único eixo.

Tabela 3. - Eficiências dos rastreadores estudados (indicados pela orientação dos eixos).

\begin{tabular}{|c|c|c|c|c|}
\hline Estudo & Estrutura & \multicolumn{2}{|c|}{ Eficiência } & Cidade \\
\hline Alcântara, 2013 & Dois eixos & - & $22,24 \%$ & Várias cidades \\
\hline \multirow{3}{*}{ Sequeira, 2011} & Dois eixos & - & $28,00 \%$ & Murça \\
\hline & Dois eixos & - & $35,00 \%$ & Sobral \\
\hline & Dois eixos & - & $40,00 \%$ & Amarelejo \\
\hline Revoredo; Ribeiro; Leitão, 2019 & Dois eixos & - & $48,50 \%$ & Rio de Janeiro \\
\hline Alves, 2008 & Dois eixos & - & $53,10 \%$ & Bauru \\
\hline \multirow{2}{*}{ Ferreira, 2017} & Dois eixos & - & $39,20 \%$ & \multirow{2}{*}{ Belo Horizonte } \\
\hline & Polar N-S & $25,00 \%$ & - & \\
\hline \multirow{2}{*}{ Trevelin, 2014} & Dois eixos & - & $39,20 \%$ & \multirow{2}{*}{ São Carlos } \\
\hline & Azimutal & $25,00 \%$ & - & \\
\hline \multirow{6}{*}{ Oliveira, 2008} & \multirow{6}{*}{ Azimutal } & $11,00 \%$ & - & Porto Alegre \\
\hline & & $7,00 \%$ & - & Aracaju \\
\hline & & $8,00 \%$ & - & São Paulo \\
\hline & & $11,00 \%$ & - & Macapá \\
\hline & & $8,00 \%$ & - & Manaus \\
\hline & & $9,00 \%$ & - & Recife \\
\hline Guarnieri, 2017 & Horizontal N-S & $18,00 \%$ & - & Várias cidades \\
\hline Filho, 2019 & Horizontal N-S & $13,81 \%$ & - & Maringá \\
\hline
\end{tabular}

Fonte: AUTOR, 2020.

\subsection{PREÇOS}

Os preços apresentados na tabela 4 foram extraídos dos trabalhos anteriores da tabela 1, dos que disponibilizaram e eram relevantes. Os valores são apresentados

RC: 103710

Disponível em: https://www.nucleodoconhecimento.com.br/engenhariaeletrica/rastreadores-solares 
em $R \$ / W$, os preços que originalmente são em outra moeda foram convertidos para Real na cotação em 06/07/2020 (Euro $R \$ 6,02$ e Dólar $R \$ 5,31$ ) apenas para comparação, sem considerar impostos e importação.

Tabela 4. - Preços dos rastreadores estudados.

\begin{tabular}{ccccccc}
\hline $\begin{array}{c}\text { Estudo/ } \\
\text { empresa }\end{array}$ & $\begin{array}{c}\text { Moeda } \\
\text { original }\end{array}$ & $\begin{array}{c}\text { Potência } \\
(\mathbf{K W p})\end{array}$ & $\begin{array}{c}\text { Fixo } \\
\mathbf{( R \$} / \mathbf{W})\end{array}$ & $\begin{array}{c}\text { Um eixo } \\
\mathbf{( R \$ / W )}\end{array}$ & $\begin{array}{c}\text { Dois } \\
\text { eixos } \\
(\mathbf{R} \$ \mathbf{W})\end{array}$ & Aumento \\
\hline Sequeira, 2011 & $€$ & 4,14 & $\mathrm{R} \$ 21,81$ & - & $\mathrm{R} \$ 26,90$ & $23 \%$ \\
\hline Alves, 2008 & $\mathrm{R} \$$ & 0,05 & $\mathrm{R} \$ 21,10$ & - & $\mathrm{R} \$ 28,63$ & $36 \%$ \\
\hline Alcântara, 2013 & $\mathrm{US} \$$ & - & $\mathrm{R} \$ 8,32$ & - & $\mathrm{R} \$ 15,22$ & $83 \%$ \\
\hline Ferreira, 2017 & $\mathrm{R} \$$ & 2,34 & $\mathrm{R} \$ 5,97$ & - & $\mathrm{R} \$ 12,08$ & $102 \%$ \\
\hline Ferreira, 2017 & $\mathrm{R} \$$ & 2,34 & $\mathrm{R} \$ 5,97$ & $\mathrm{R} \$ 10,91$ & - & $83 \%$ \\
\hline Filho, 2019 & $\mathrm{R} \$$ & 8,76 & $\mathrm{R} \$ 5,36$ & $\mathrm{R} \$ 6,37$ & - & $19 \%$ \\
\hline Guarnieri, 2017 & $\mathrm{R} \$$ & 90000 & $\mathrm{R} \$ 2,63$ & $\mathrm{R} \$ 3,00$ & - & $14 \%$ \\
\hline
\end{tabular}

Fonte: AUTOR, 2020.

$\mathrm{Na}$ coluna Aumento, são mostradas as porcentagens de aumento de preço entre a estrutura fixa e com rastreador. A média de aumento no preço para dois eixos foi de $61 \%$ e para um eixo foi de $38 \%$. Para não causar divergências, foram calculadas as médias dos projetos de duplo eixo separadas dos de único eixo com suas respectivas estruturas fixas.

\subsection{MANUTENÇÃO}

O valor de manutenção anual das estruturas foi baseado em Sequeira (2011), onde para uma estrutura fixa gasta $€ 100,00$ em 14 anos e $€ 150,00$ nos 5 últimos e com a estrutura de rastreador $€ 150,00$ em 14 anos e $€ 200,00$ nos 5 últimos em uma vida útil de 20 anos, isso dá em médias anuais de $€ 107,50$ e $€ 155,00$ para uma potência instalada de 4,14KWp. Portanto, o preço por watt da manutenção é de 0,156 R \$/W para sistemas fixos e 0,225 $R \$ / W$ para trackers de duplo eixo. Obedecendo a proporção dos preços das estruturas, foi deduzida a manutenção dos sistemas de

RC: 103710

Disponível em: https://www.nucleodoconhecimento.com.br/engenhariaeletrica/rastreadores-solares 
único eixo, aumentando assim $38 \%$ do valor da manutenção do sistema fixo e obtendo o valor de $0,215 \mathrm{R} \$ / \mathrm{W}$.

\subsection{CONSUMO DO TRACKER}

$\mathrm{Na}$ tabela 5, vemos o consumo do sistema de tracker em $\mathrm{KWh} /$ dia que foram obtidos dos estudos. Foram incluídas duas marcas - Huayue (SHANDONG, 2020) e Sat Control (SAT, 2020) - que foram pesquisadas na internet.

Tabela 5. - Consumo dos rastreadores.

\begin{tabular}{|c|c|c|c|c|c|c|}
\hline Marca & Fonte & Tipo & $\begin{array}{l}\text { Potência } \\
(\mathrm{KWp})\end{array}$ & $\begin{array}{l}\text { Geração } \\
\text { (KWh/dia) }\end{array}$ & $\begin{array}{l}\text { Consumo } \\
\text { do tracker } \\
\text { (KWh/dia) }\end{array}$ & $\begin{array}{l}\text { Porcentagem } \\
\text { do consumo }\end{array}$ \\
\hline Satcontrol & Satcontrol & $\begin{array}{l}2 \\
\text { eixos }\end{array}$ & 4,5 & 18,83 & 0,01752 & $0,0931 \%$ \\
\hline Huayue & Huayue & $\begin{array}{l}2 \\
\text { eixos }\end{array}$ & 32 & 133,89 & 1,50000 & $1,1203 \%$ \\
\hline Mecasolar & $\begin{array}{l}\text { Alcântara, } \\
2013\end{array}$ & $\begin{array}{l}2 \\
\text { eixos }\end{array}$ & 7 & 29,29 & 0,15000 & $0,5122 \%$ \\
\hline Feina SF09 & $\begin{array}{l}\text { Ferreira, } \\
(2017)\end{array}$ & $\begin{array}{l}2 \\
\text { eixos }\end{array}$ & 2,34 & 11,44 & 0,00300 & $0,0262 \%$ \\
\hline Huayue & Huayue & Horiz. & 72 & 301,25 & 1,00000 & $0,3320 \%$ \\
\hline Romagnole & $\begin{array}{l}\text { Filho, } \\
\text { (2019) }\end{array}$ & Horiz. & 1000 & 4184 & 5,00000 & $0,1195 \%$ \\
\hline $\begin{array}{l}\text { Etatrack } \\
1000-30 \\
\text { Lorentz }\end{array}$ & $\begin{array}{l}\text { Ferreira, } \\
(2017)\end{array}$ & polar & 2,34 & 10,27 & 0,00274 & $0,0267 \%$ \\
\hline
\end{tabular}

Fonte: AUTOR, 2020. 
A geração de energia do sistema fotovoltaico, salvo os valores fornecidos pelos experimentos, foram calculadas de acordo com a expressão utilizada por Soares, et al (2020), onde pode-se determinar a energia gerada pelos painéis fotovoltaicos através da potência de pico instalada pela expressão (9). Foi utilizado pelo autor um rendimento de $80 \%$ sem considerar perdas de eficiência das células por temperatura. A irradiação solar média mensal adotada foi de $5,23 \mathrm{KW} / \mathrm{m}^{2}$.dia, da cidade de Bauru (coordenadas $22,301^{\circ} \mathrm{S}, 49,049^{\circ} \mathrm{O}$ ), para um ângulo igual a latitude, de acordo com o site do Centro de Referência para as Energias Solar e Eólica Sérgio de S. Brito (CRESESB), (POTENCIAL, 2020).

$$
E_{G}=P_{P} R I
$$

Onde $E_{G}$ é a energia gerada, Pp é a potência de pico instalada $(K W p), R$ é o rendimento médio e I a irradiação solar média mensal do local em questão.(9)

A porcentagem do consumo é calculada com base na potência de geração do sistema. Com esses valores foi obtida uma média de 0,4379\% para dois eixos e $0,1594 \%$ para sistemas de um eixo.

\section{ESTUDO DE VIABILIDADE E COMPARAÇÃO}

Para verificar a viabilidade e comparar os investimentos em questão, foram utilizadas algumas técnicas que auxiliam na tomada de decisão, como o Valor Presente Líquido (VPL), a Taxa Interna de Retorno (TIR) e o Payback.

\subsection{VPL}

O VPL, segundo Silva (2018), é utilizado para trazer os valores futuros dos retornos do investimento para a data zero baseado em uma Taxa Mínima de Atratividade (TMA), ele é calculado através da expressão (10).

RC: 103710

Disponível em: https://www.nucleodoconhecimento.com.br/engenhariaeletrica/rastreadores-solares 


$$
V P L=\sum_{j=1}^{t} \frac{c_{j}}{(1+k)^{j}}-c_{i}
$$

Onde $c_{j}$ é o capital de retorno, $c_{i}$ o capital de investimento, $k$ é a TMA e $j$ é o período, em um somatório em um tempo $t$.

Com o VPL $=0$, os retornos do investimento são iguais à TMA e se são positivos, a taxa de retorno é maior que a TMA.

\subsection{TIR}

A Taxa Interna de Retorno (TIR), demonstrada pela expressão (11), é a taxa com que um investimento inicial retorna, trazendo os valores futuros para o presente. Portanto, é atrativo um investimento que possui um TIR maior que a TMA.

$$
\sum_{j=1}^{n} \frac{c_{j}}{(1+T I R)^{j}}-c_{i}=0
$$

Onde as variáveis são as mesmas da expressão (10). Igualando-se a equação com $c$, é possível determinar a taxa de retorno desse investimento.

RC: 103710

Disponível em: https://www. nucleodoconhecimento.com.br/engenhariaeletrica/rastreadores-solares 


\subsection{PAYBACK}

O payback, calculado com a expressão (12), é utilizado para saber o tempo que um investimento vai ser pago através de seu retorno.

$$
\text { Payback }=\frac{\text { investimento inicial }}{\text { retorno por período }}
$$

As expressões apresentadas auxiliaram na comparação entre os investimentos em rastreadores de duplo ou único eixo, baseando-se em qual proporciona um VPL e TIR maiores e payback menor, justificando a escolha.

\section{CÁLCULO DE VIABILIDADE}

Para a TMA, foi adotada a taxa Selic, que no período estava em $2,25 \%$ ao ano, a base de tempo foi baseada na vida útil média dos sistemas fotovoltaicos, 25 anos de acordo com os fabricantes Sat control e Huayue New Energy. No primeiro cenário foram utilizadas as médias encontradas anteriormente. Os preços médios foram obtidos calculando os projetos fixos da tabela 4 e multiplicado pela média de aumento $61 \%$ e $38 \%$, como mostra a tabela 6 .

Tabela 6. - Média de preços conforme estrutura.

\begin{tabular}{|c|c|c|c|}
\hline $\begin{array}{l}\text { Estudo/ } \\
\text { empresa }\end{array}$ & Fixo $(\mathrm{R} \$ / \mathrm{W})$ & Um eixo $(R \$ / W)$ & Dois eixos $(\mathrm{R} \$ / \mathrm{W})$ \\
\hline Sequeira, 2011 & $\mathrm{R} \$ 21,81$ & $\mathrm{R} \$ 30,10$ & $\mathrm{R} \$ 35,12$ \\
\hline Alves, 2008 & $\mathrm{R} \$ 21,10$ & $\mathrm{R} \$ 29,12$ & $\mathrm{R} \$ 33,97$ \\
\hline $\begin{array}{l}\text { Alcântara, } \\
2013\end{array}$ & $\mathrm{R} \$ 8,32$ & $\mathrm{R} \$ 11,48$ & $\mathrm{R} \$ 13,40$ \\
\hline Ferreira, 2017 & $\mathrm{R} \$ 5,97$ & $\mathrm{R} \$ 8,24$ & $\mathrm{R} \$ 9,62$ \\
\hline Ferreira, 2017 & $\mathrm{R} \$ 5,97$ & $\mathrm{R} \$ 8,24$ & $\mathrm{R} \$ 9,62$ \\
\hline
\end{tabular}

RC: 103710

Disponível em: https://www.nucleodoconhecimento.com.br/engenhariaeletrica/rastreadores-solares 


\begin{tabular}{|l|l|l|l|}
\hline Filho, 2019 & $R \$ 5,36$ & $R \$ 7,40$ & $R \$ 8,63$ \\
\hline $\begin{array}{l}\text { Guarnieri, } \\
\text { 2017 }\end{array}$ & $R \$ 2,63$ & $R \$ 3,63$ & $R \$ 4,24$ \\
\hline
\end{tabular}

Fonte: AUTOR, 2020.

Com isso, as médias obtidas foram 10,17 R\$/W para os sistemas fixos, 14,03 $R \$ / W$ para sistemas de único eixo e 16,37 R\$/W para sistemas de duplo eixo. A tabela 7 mostra os valores utilizado no cenário 1 .

Tabela 7. - Cenário 1: Médias utilizadas para o cálculo de viabilidade.

\begin{tabular}{|l|l|l|l|}
\hline & Fixo & Um eixo & Dois eixos \\
\hline Preço & $10,17 \mathrm{R} \$ / \mathrm{W}$ & $14,03 \mathrm{R} \$ \mathrm{~W}$ & $16,37 \mathrm{R} \$ \mathrm{~W}$ \\
\hline Eficiência & - & $13,58 \%$ & $38,16 \%$ \\
\hline Manutenção & $0,156 \mathrm{R} \$ / \mathrm{W}$ & $0,215 \mathrm{R} \$ / \mathrm{W}$ & $0,225 \mathrm{R} \$ \mathrm{~W}$ \\
\hline Consumo & - & $0,1594 \%$ & $0,4379 \%$ \\
\hline
\end{tabular}

Fonte: AUTOR, 2020.

Com essa configuração, uma instalação de $10 \mathrm{KWp}$ fixa custaria $R \$ 101.700,00$ e necessitaria de uma manutenção de $R \$ 1.560,00$ ao ano, retornando $R \$ 9.457,38$ ao ano de acordo com a equação (9) menos os gastos, que daria $R \$ 8.028,73$. A tarifa de energia elétrica utilizada foi a cobrada pela CPFL na data e local desse projeto de $0,62788 \mathrm{R} \$ / \mathrm{KWh}$, valor este para uma categoria residencial. Somente a estrutura de um tracker de dois eixos (desconsiderando a parte fixa), custaria $R \$ 62.000,00$, com manutenção de $R \$ 690,00$ e consumo de $R \$ 41,99$, retornando $R \$ 3.608,94$ menos os gastos, resultando em $R \$ 2.927,07$. Portanto o total gerado, considerando as parcelas da parte fixa e da estrutura, calculado pela equação (13) foi de $\mathrm{R} \$ 10.955,80$. 


\section{Energia gerada $=$ Geração total - Manutenção total - Consumo}

Com esses valores foi obtido para o sistema fixo um VPL de $\mathrm{R} \$ 50.543,89$, TIR de $6,10 \%$ e payback de 12,67 anos, porém para o tracker o VPL foi de $R \$-6.495,76$, TIR $1,32 \%$ e payback de 21,18 anos.

Para o tracker de um eixo, o custo de instalação somente da estrutura seria $\mathrm{R} \$$ $38.600,00$ (o custo somente do tracker foi obtido subtraindo o custo da instalação fixa do total da instalação com o rastreador), a manutenção $R \$ 590,00$ e consumo $R \$ 15,28$, retornando um valor de $R \$ 1.284,31$ menos os gastos, gerando $R \$$ 696,87 , somando esses valores à parte fixa, de acordo com a equação 13, energia total gerada seria de $R \$ 8.725,60$. Nessa situação o VPL somente do rastreador seria de $R \$-25.385,77$, TIR $-5,37 \%$ e payback de 55,39 anos.

Os dois tipos de estruturas se mostraram inviáveis na configuração adotada, uma vez que os valores de VPL foram negativos e o payback do investimento aumentado por conta do ratreador.

$\mathrm{Na}$ tabela 8 foram calculados o VPL, TIR e payback totais dos estudos mencionados na tabela 5 e mantendo as eficiências, os custos de manutenção e consumo, alterando somente os preços.

Tabela 8. - VPL, TIR e Payback dos estudos.

\begin{tabular}{|l|l|l|l|l|l|l|}
\hline Estudo/empresa & Fixo & \multicolumn{5}{|l|}{ Tracker } \\
\cline { 2 - 6 } & VPL & TIR & Payback & VPL & TIR & Payback \\
\hline Sequeira & $-\mathrm{R} \$$ & $-0,63 \%$ & 27,16 & $\mathrm{R} \$$ & $3,01 \%$ & 17,39 \\
\hline $\mathbf{2 0 1 1 )}$ & $65.856,11$ & & & $4.604,24$ & & \\
\hline Alves (2008) & $-\mathrm{R} \$$ & $-0,38 \%$ & 26,28 & $-\mathrm{R} \$$ & $-0,22 \%$ & 25,73 \\
& $58.756,11$ & & & $19.795,76$ & & \\
\hline Alcântara & $\mathrm{R} \$$ & $8,35 \%$ & 10,36 & $-\mathrm{R} \$$ & $0,46 \%$ & 23,57 \\
\hline
\end{tabular}

RC: 103710

Disponível em: https://www.nucleodoconhecimento.com.br/engenhariaeletrica/rastreadores-solares 


\begin{tabular}{|c|c|c|c|c|c|c|}
\hline (2013) & $69.043,89$ & & & $13.495,76$ & & \\
\hline Ferreira (2017) & $\begin{array}{l}\mathrm{R} \$ \\
92.543,89\end{array}$ & $12,78 \%$ & 7,44 & $\begin{array}{l}-R \$ \\
5.595,76\end{array}$ & $1,44 \%$ & 20,87 \\
\hline Ferreira (2017) & $\begin{array}{l}\mathrm{R} \$ \\
92.543,89\end{array}$ & $12,78 \%$ & 7,44 & $\begin{array}{l}-\mathrm{R} \$ \\
36.185,77\end{array}$ & $-6,81 \%$ & 70,89 \\
\hline Filho (2019) & $\begin{array}{l}\mathrm{R} \$ \\
98.643,89\end{array}$ & $14,47 \%$ & 6,68 & $\begin{array}{l}\mathrm{R} \$ \\
3.114,23\end{array}$ & $4,72 \%$ & 14,49 \\
\hline $\begin{array}{l}\text { Guarnieri } \\
(2017)\end{array}$ & $\begin{array}{l}\mathrm{R} \$ \\
125.943,89\end{array}$ & $30,49 \%$ & 3,28 & $\begin{array}{l}R \$ \\
9.514,23\end{array}$ & $18,57 \%$ & 5,31 \\
\hline
\end{tabular}

Fonte: AUTOR, 2020

Vemos que para Sequeira, 2011 e Alves, 2008, o projeto é inviabilizado já na parte fixa, pois contém VPLs e TIRs negativos, em Alcântara (2013) e Ferreira (2017), o VPL dos trackers também são negativos, apesar da estrutura fixa serem viáveis. Em Filho (2019) e Guarnieri (2017), apesar dos investimentos serem viáveis em termos de VPL e TIR, tornam-se inviáveis pois aumentam o payback do investimento.

Um cenário positivo foi criado como exemplo utilizando os custos de instalação de Guarnieri (2017), que utiliza um rastreador de um eixo e o maior ganho para essa estrutura, de 25\%, encontrado em Ferreira (2017) e Trevelin (2014), para uma instalação de $10 \mathrm{KWp}$, os valores são mostrados na tabela 9. Foram mantidos os valores de manutenção e consumo.

Tabela 9. - Cenário positivo.

\begin{tabular}{|c|c|c|c|c|}
\hline & Fixa & Tracker & Totá & \\
\hline Preço & 2,63 & 0,37 & $\mathrm{R} \$$ & 5,63 \\
\hline Custo & $\mathrm{R} \$ \quad 26.300,00$ & $R \$ \quad 3.700,00$ & $\mathrm{R} \$$ & $30.000,00$ \\
\hline Eficiência & - & $25 \%$ & - & \\
\hline Retorno & $\mathrm{R} \$ 8.028,73$ & $\mathrm{R} \$ \quad 1.791,90$ & $\mathrm{R} \$$ & $9.820,63$ \\
\hline
\end{tabular}

RC: 103710

Disponível em: https://www.nucleodoconhecimento.com.br/engenhariaeletrica/rastreadores-solares 


\begin{tabular}{|l|l|l|l|}
\hline VPL & $\mathrm{R} \$ 125.943,89$ & $\mathrm{R} \$ 30.278,67$ & $\mathrm{R} \$ 156.222,56$ \\
\hline TIR & $30,49 \%$ & $48,43 \%$ & $32,71 \%$ \\
\hline Payback & 3,28 & 2,06 & 3,05 \\
\hline
\end{tabular}

Fonte: AUTOR, 2020.

Vemos que, no caso exemplificado, o investimento do tracker se torna viável, pois possui VPLs positivos, TIRs maiores que a TMA e o payback do tracker é menor que da estrutura fixa, o que impacta no resultado total e diminui o tempo de retorno do investimento.

\section{CONCLUSÃO}

Foi verificado que os projetos dos estudos se mostraram inviáveis com as suas configurações, bem como a média do total gerada por eles. Considerando TIR e VPL viáveis, um ponto crítico de escolha mostrado na equação (14) é quando o payback do tracker se iguala ao do sistema fixo, nesse ponto não se ganha nem perde com a utilização do rastreador, portanto, o projeto torna-se interessante a partir de quando o payback do tracker começa a ser menor que da estrutura fixa, pois assim, se consegue diminuir o tempo de retorno do projeto total (estrutura fixa mais o tracker).

$$
\frac{\text { Investimento } f}{\text { Gerado } f-\text { Manutenção } f}>\frac{\text { Investimento } t}{\text { Gerado } t-\text { Manutenção } t-\text { Consumo } t}
$$

Onde os índices $f$ e $t$ significam fixo e tracker.

Portanto, as variáveis que influenciam na diminuição do payback de um rastreador são o custo de investimento, a eficiência do tracker, o custo com manutenção, e o consumo.

RC: 103710

Disponível em: https://www.nucleodoconhecimento.com.br/engenhariaeletrica/rastreadores-solares 
O cenário positivo exemplificado na tabela 9 , mostra que é possível atualmente conseguir uma viabilidade na instalação de um rastreador solar em uma estrutura fotovoltaica, buscando boas eficiências e preços, pois são os fatores que mais influenciam na viabilidade. Outro fator importante que contribui para a diminuição dos custos é o tamanho do projeto, foi visto na tabela 2 uma tendência na queda dos preços conforme o aumento da potência instalada, isso faz com que diminua não somente os custos de investimento como também torna a manutenção mais barata e um consumo por KWp menor.

Outro ponto importante é a tendência vista na tabela 8 , onde os rastreadores de único eixo são os mais viáveis quando comparados com trackers de dois eixos, isso mostra que em uma eventual escolha de estrutura, o primeiro, na maioria dos casos, mostra-se mais vantajoso apesar de apresentar uma eficiência menor.

Com o passar do tempo os painéis geradores ficam cada vez mais baratos, visto que é possível encontrar kits de geração mais baratos que a média encontrada nesse artigo, assim o interesse por trackers tende a ser menor por ser mais difícil de abaixar o custo das estruturas, mas vivemos em um cenário em que ainda se encontra viabilidade nesse tipo de investimento, portanto é válido uma análise em cada caso, uma vez que os preços e eficiências mudam rapidamente com o passar do tempo.

\section{REFERÊNCIAS}

ALCÂNTARA, É. C. de. Ferramenta para estimar o desempenho de sistemas fotovoltaicos com diferentes estruturas de inclinação e tecnologias - Uma análise comparativa do ganho proveniente da utilização de seguidor de Sol e concentrador solar. 117 p. Trabalho de conclusão de curso (Engenharia Elétrica). Departamento de Engenharia Elétrica, Universidade de Brasília, Brasília, 2013.

RC: 103710

Disponível em: https://www.nucleodoconhecimento.com.br/engenhariaeletrica/rastreadores-solares 
ALVES, A. F. Desenvolvimento de um sistema de posicionamento automático para painéis fotovoltaicos. 153 p. Tese (Doutorado em Agronomia). - Faculdade de Ciências Agromômicas, Universidade Estadual Paulista, Botucatu, 2008.

DATA \& Statistics. International Renewable Energy Agency (IRENA), 2019. Disponível em: < https://www.irena.org/Statistics>. Acesso em: 26 jun. 2020.

FERREIRA, T. E. Análises de custos e de viabilidade econômica para sistemas fotovoltaicos: painéis fixos e painéis móveis. 37 p. Monografia (Especialização em Eficiência Energética Aplicada aos Processos Produtivos. - Universidade Federal de Santa Maria, Novo Hamburgo, 2017.

FILHO, C. C. U. Análise de viabilidade do sistema seguidor solar de um eixo horizontal para geradores fotovoltaicos. 11 p. Artigo (Graduação em Engenharia Elétrica). - Unicesumar, Maringá, 2019.

GERAÇÃO Distribuída. ANEEL, 2015. Disponível em: < www.aneel.gov.br/geracaodistribuida>. Acesso em: 25 jun. 2020.

GLOBAL Solar Atlas. Global Solar Atlas, 2020. Disponível em: < globalsolaratlas.info>. Acesso em: 26 jun. 2020.

GUARNIERI, M. V. Usinas solares fotovoltaicas com seguimento em um eixo no Brasil: aspectos da construção, custos e expectativa de desempenho. $180 \mathrm{p}$. Dissertação (Mestrado em Engenharia Civil). - Universidade Federal de Santa Catarina, Florianópolis, 2017.

GUTIERREZ, Sebastian. et al. Development and testing of a single-axis photovoltaic sun tracker through the internet of things. Energies, Basel, Suíça, v. 13, n. 2547, 2020. Disponível em <mdpi.com>. Acesso em: 08 jun. 2020.

KALOGIROU, Soteris A. Solar Energy Engineering. Processes and Systems. 2. ed. Kidlington: Academic Press, 2014. 
OLIVEIRA, M. M. Análise de desempenho de um gerador fotovoltaico com seguidor solar azimutal. 132 f. Dissertação (Mestrado em Engenharia). Universidade Federal do Rio Grande do Sul, Porto Alegre, 2008.

PINHO, J. T.; GALDINO, M. A. Manual de Engenharia para Sistemas Fotovoltaicos. 2. ed. Rio de Janeiro: CEPEL - CRESESB, 2014.

POTENCIAL Solar - CRESESB. Diponível em: $<$ http://www.cresesb.cepel.br/index.php?section=sundata\&>. Acesso em: 11 jun. 2020.

RENEWABLE Energy Data Book. National Renewable Energy Laboratory (NREL), 2018. Disponível em: <nrel.gov>. Acesso em: 26 jun. 2020.

REVOREDO T. C; RIBEIRO M. V. S.; LEITÃO P. L. M. Especificação e prototipagem de um sistema de microgeração fotovoltaica com rastreamento solar. Revista Brasileira de Energia Solar, Rio de Janeiro, v. 10, n. 1, 2019. Disponível em <rbens.emnuvens.com.br>. Acesso em: 09 maio 2020.

SAT Control. Disponível em: $\quad$ http://www.solarmotors.com/?gclid=EAlalQobChMllsyTu4TK6QIViJWzCh3XqwHvEAAYASAAEgIDN PD_BwE>. Acesso em: 21 maio 2020.

SEQUEIRA, A. R. P. Microgeração fotovoltaica. Análise da viabilidade técnicoeconômica. 88 p. Relatório de estágio (Mestrado em Engenharia do Ambiente). Universidade Católica Portuguesa, Porto, Portugal, 2011.

SHANDONG Huayue New Energy Co., Ltd. Disponível em: $<$ https://uniquesolar.en.alibaba.com/?spm=a2700.details.cordpanyb.4.6740dfWvdfW $v D j>$. Acesso em: 22 maio 2020.

SILVA, J. S. da. Equações algébricas e progressões geométricas utilizadas nos métodos de decisão de investimentos baseados no VLP e TIR. 60 p. Dissertação 
(Mestrado em Matemática). - Universidade Tecnológica Federal do Paraná, Curitiba, 2018.

SOARES P. M. et al. Avaliação econômica e técnica de um sistema conectado à rede: estudo de caso de condomínio na cidade de Brasília, Brasil. Brazilian Journal of Development, Cutitiba, v. 6, n. 6, 2020. Disponível em < https://www.brazilianjournals.com/>. Acesso em: 11 jun. 2020.

TREVELIN, F. C. Estudo comparativo entre métodos de rastreamento solar aplicados a sistemas fotovoltaicos. $55 \mathrm{p}$. Trabalho de Conclusão de Curso (Engenharia Elétrica). - Universidade de São Paulo, São Carlos, 2014.

Enviado: Janeiro, 2021.

Aprovado: Dezembro, 2021. 